\title{
Development of an STS map of an interspecific progeny of Malus
}

\author{
F. Fernández-Fernández • K. M. Evans • J. B. Clarke • \\ C. L. Govan - C. M. James • S. Marić • K. R. Tobutt
}

Published online: 21 February 2008

(C) Springer-Verlag 2008

Erratum to: Tree Genetics \& Genomes

DOI 10.1007/s11295-007-0124-y

In the authors list, for S. Marič, read S. Marić. Similarly in the acknowledgments for S. Marič, read S. Marić

The online version of the original article can be found at http://dx.doi. org/10.1007/s11295-007-0124-y.

F. Fernández-Fernández $(\bowtie) \cdot$ K. M. Evans $\cdot$ J. B. Clarke $\cdot$

C. L. Govan - C. M. James · S. Marić · K. R. Tobutt

East Malling Research (EMR),

New Road, East Malling,

Kent ME19 6BJ, UK

e-mail: felicidad.fernandez@emr.ac.uk 